fications of cadmium between $0^{\circ}$ and $100^{\circ}$. Cohen and Helderman deduced from Equations $I$ and 3 found by them (as well as by Getman) for their $\alpha$-and $\gamma$-cells, respectively, that the metastable transition point $\mathrm{Cd}_{\gamma} \rightarrow \mathrm{Cd}_{\alpha}$ lies at $94.8^{\circ}$.

Although we know that the transition temperature of $\mathrm{Cd}_{\alpha} \rightleftarrows \mathrm{Cd}_{\beta}$ lies between $0^{\circ}$ and $100^{\circ}$, we are not allowed to conclude that there exist more than 2 stable modifications within this range of temperatures. We found that the $\gamma$ modification is always metastable within this range and Getman who used this modification in his $\gamma$-cells evidently agrees with this opinion. Consequently his words: "the results of the present investigation, however, seem to render the existence of more than two allotropic modifications of cadmium between $0^{\circ}$ and $100^{\circ}$ extremely doubtful," lose their significance. Three different forms of cadmium may exist between $0^{\circ}$ and $100^{\circ}$ but one of these $\left(\mathrm{Cd}_{\gamma}\right)$ is always metastable within this range of temperatures.

\title{
Summary.
}

I. It has been demonstrated that in the assumptions made by Getman in his paper on the allotropy of cadmium some mistakes have crept in. Consequently the conclusions which he has drawn from his careful experimental work ought to be revised.

2. If these mistakes are removed Getman's results become identical with those obtained by Cohen and Helderman. In this way Getman's work has been a very welcome control as well as a confirmation of the results formerly got by ourselves.

UTRECHT, HOLI,AND.

[CONTRIBUtion From the BUREAU OF CHEMistry, U.S. DEPARTMENT OF Agriculture.]

\section{A STUDY OF THE ELECTRICAL CONDUCTANCE OF AQUEOUS PHTHALATE SOLUTIONS.}

By Harrison E. Patten, Alfred J. Johnson and Garald h. Matns.

Received March 5, 1918.

Introduction.

Acid potassium phthalate is an excellent standard in the preparation of solutions with definite hydrogen-ion concentration. The titration curve of phthalic acid shows but a very slight irregularity at the point of neutralization of the first hydrogen ion, so that the hydrogen-ion concentration of a solution decreases regularly with the addition of an alkali, almost until the normal salt is formed. Clark and Lubs ${ }^{1}$ have made a study of the hydrogen electrode potentials in o. I $M$ solution of acid potassium phthalate with varying amounts of sodium hydroxide and hydrochloric acid, and gives the composition of mixtures differing by intervals of $0.2 P_{\mathrm{H}}$ for use as standard comparison solutions in the colorimetric 
determination of hydrogen-ion concentrations between $2.2 P_{\mathrm{HI}}$ and $6.2 P_{\mathrm{H}}$.

Acid potassium phthalate is readily crystallizable from aqueous solution without water of crystallization and can be dried at a temperature of $110^{\circ}$. On account of its high molecular weight and ease with which it can be obtained in a high degree of purity it is also an excellent substance for use in the standardization of alkali solutions. In o. I $M$ solution the alkali salt $\mathrm{NaKC}_{8} \mathrm{H}_{4} \mathrm{O}_{4}$ has a $P_{\mathrm{H}}$ value of about $8,{ }^{1}$ so that with phenolphthalein it produces the pink color at the point of formation of the normal salt.

In view of this importance of potassium acid phthalate as a standard in acidimentary and hydrogen-ion concentration work, it was deemed advisable to increase our knowledge of the properties of its solutions. One of these properties, the specific electrical conductance, has been studied, together with its derived value, the molecular conductivity; and an attempt made to evaluate the molecular conductivity at infinite dilution. This has the further bearing that a knowledge of the dissociation constant for the various ions of organic acids and salts is much needed; as indeed it is for all polybasic acids.

In this connection it was found necessary to determine the conductivity of normal potassium phthalate.

\section{Experimental.}

The set-up of the apparatus is shown schematically in Fig. I. The terminals of a Kohlrausch slide wire bridge, $A B$, with extension coils are grounded through two resistances of I0,000 ohms each. The standard resistance $R$ is of the dial type and has a range from $0.1 \mathrm{ohm}$ to 100,000 ohms with Curtis non-inductance coils in the higher steps. In series with the standard resistance is a fixed induction, $I$, whose inductance is greater than the lowest value of the variable inductance $V_{I}$ which is in series with the conductivity cell $\mathrm{C}$. A "wireless" telephone receiver, $T$, is used in getting the point of balance. The alternating current is obtained from a Siemens-Schuckert high-frequency generator, which is placed in a distant room. The motor $\mathrm{V}$ drives the armature $\mathrm{H}$ between the arms of the generator $G$, which has a primary or field winding in series with a regulating rheostat and an ammeter $A_{1}$. In these measurements current was obtained from 6 storage batteries and the rheostat adjusted until a current of 0.5 ampere was indicated by the ammeter. By means of slip rings an alternating current is taken from the direct current armature and led to the Frahm vibrating reed frequency indicator $N$. The brake load rheostat $P$, connected to the slip rings of the armature, is used for the final adjustment of the frequency. The secondary side of the generator has two windings which may be used singly, or joined in series, or

${ }^{1}$ Loc. cit. 
parallel. The drawing shows them connected in parallel. In this work, however, only one coil was used, a resistance consisting of a carbon lamp was connected across the second coil. For obtaining resonance the varia-

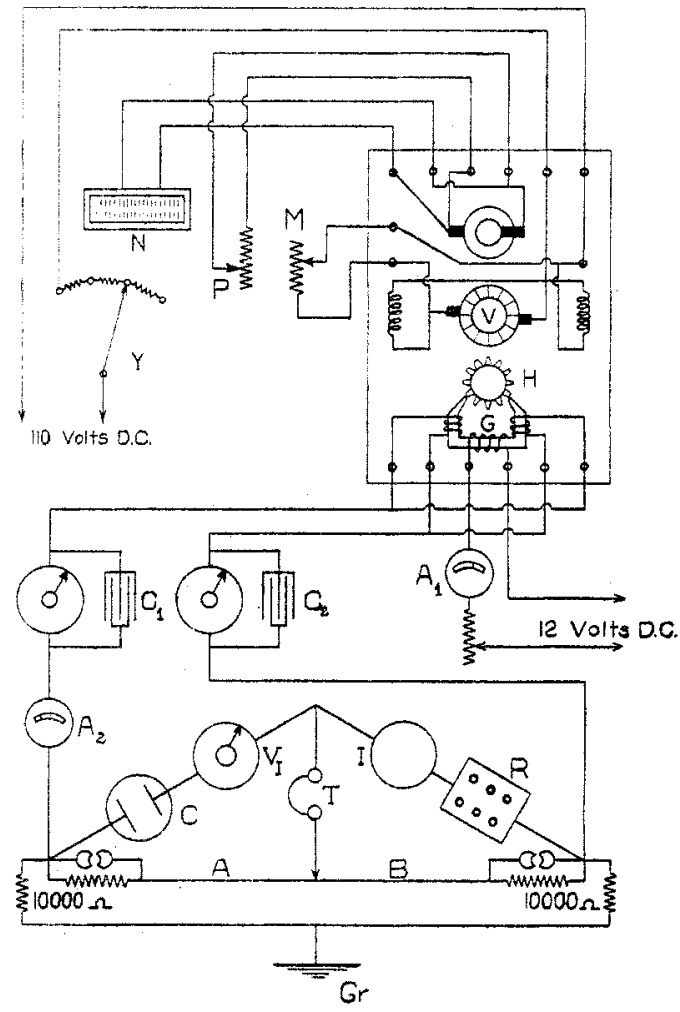

Fig. I.

AB-bridge wire.

$A_{1}$-ammeter primary circuit. (Exciting field.)

$\mathrm{A}_{2}$-hot-wire ammeter to get resonance in secondary circuit.

$\mathrm{C}$-conductivity cell.

$\left.\begin{array}{l}\mathrm{C}_{1} \\ \mathrm{C}_{2}\end{array}\right\}$-resonating condensers.

$\mathrm{N}$-frequency indicator.

$\mathrm{R}$-standard variable resistance box.
$\mathrm{I}$-fixed inductance.

$\mathrm{V}_{\mathrm{I}}^{-}$--variable inductance.

G-high-frequency indicator.

$\mathrm{H}$ - armature.

$\mathrm{Y}$-regulating theostat for rough adjustment of motor speed.

$M$-regulating rheostat.

$P$-brake load.

$\mathrm{T}$ - telephone receiver.

ble twin condensers $C_{1}, C_{2}$ in series with the hot-wire ammeter $A_{2}$ were used. Resonance was obtained by adjusting $C_{1}, C_{2}$ until the ammeter gave a maximum reading. This ammeter was made in this laboratory. The plan is shown in Fig. 2.

Between the binding posts $A$ and $B$ is stretched a piece of fine nichrome wire ( 33 B. \& S. gauge). From the middle of this a second wire is attached to the balance wheel $\mathrm{C}$ taken from an alarm clock. An aluminum strip, D, 
attached to the wheel serves as the indicator on the scale $E$. When no current is flowing through the wire between $A$ and $B$ it is at room temperature and draws the wheel against the opposing hairspring $F$, and the zero reading is indicated. When the current is sent through the wire heats up and the indicator moves over the scale proportionally to the amount of current. The instrument is boxed to avoid air currents and the scale $\mathrm{E}$ is read through a glass window.

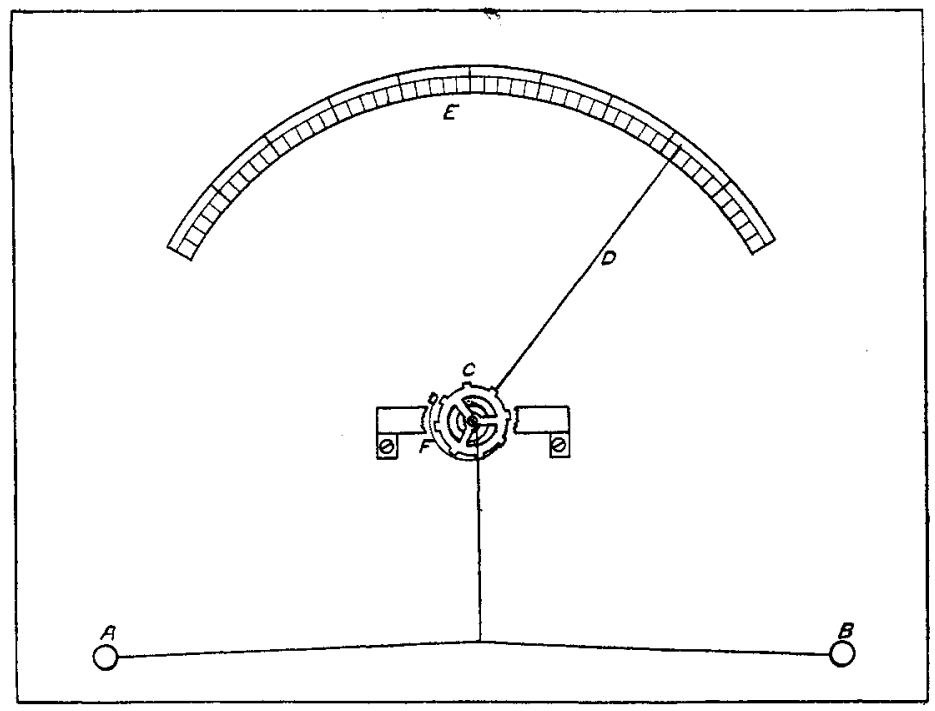

Fig. 2.

Hot-Wire Ammeter.

$A, B$, binding posts; $C$, balance wheel from alarm clock; $D$, aluminum strip indicator; $E$, scale; $F$, hairspring.

The Acree type of conductivity cell, ${ }^{1}$ with ground glass immersion stoppers, was used. The platinum electrodes were about $3 \mathrm{~cm}$. diameter and $5 \mathrm{~cm}$. apart, and were covered with platinum black. For measuring the conductivity of the conductivity water used and the more dilute solutions an Acree cell with electrodes about $6 \mathrm{~mm}$. apart was used. All measurements were made at a temperature of $25.00 \pm 0.02^{\circ}$, and a frequency of $\mathrm{I} 500$ per second.

\section{Potassium Acid Phthalate.}

Potassium acid phthalate was recrystallized several times from conductivity water and kept in a desiccator over phosphorus pentoxide for several weeks before being used. Two sets of solutions were made up: one set was made from the original $0.2 M$ solution by successive dilutions up to a dilution of $0.000 \mathrm{I} M$; the other set was made up by weighing out portions of the original salt and making up to the proper volume.

1 This Journal, 38, 2403 (Igr6). 
The measurements obtained from the two series checked very well and the data given in the table are the means of the values obtained.

TAble I.-Conductivity of Acid Potassium Phthalate.

$\begin{array}{rcccc}V . & \text { Sp. cond. } \times 10_{3} . & \begin{array}{c}\text { Mol. cond. } \\ \text { uncorrected. }\end{array} & \begin{array}{c}\text { Mol. cond. } \\ \text { corrected } \\ \text { for cond. } \mathrm{H}_{2} \mathrm{O} .\end{array} & \begin{array}{c}\text { Mol. cond. } \\ \text { partly } \\ \text { corrected.1 }\end{array} \\ 5 & 15.38 & 76.9 & 76.9 & 76.9 \\ 10 & 8.39 & 83.9 & 83.9 & 83.9 \\ 20 & 4.47 & 89.4 & 89.4 & 89.4 \\ 50 & 1.916 & 95.8 & 95.7 & 95.8 \\ 100 & 1.002 & 100.2 & 100 . \mathrm{I} & 100.1 \\ 200 & 0.521 & 104.2 & 103.9 & 104.1 \\ 500 & 0.225 & 112.5 & 111.8 & 112.2 \\ 1000 & 0.1209 & 120.9 & 119.5 & 120.2 \\ 2000 & 0.0659 & 131.8 & 129.0 & 130.4 \\ 5000 & 0.02982 & 149.1 & 142.0 & 146.0 \\ 10000 & 0.0167 & 167.0 & 153.0 & 160.0\end{array}$

It is seen from an examination of the table that the limiting molecular conductivity of potassium acid phthalate has not been even approximately attained in the most dilute solutions that were measured. Even after the total specific conductance of the water used has been deducted there is a large increase in molecular conductivity with each successive dilution.

Hydrogen-Ion Concentration.-Hydrogen electrode measurements were made for the 0.2 and $0.1 M$ solutions of potassium acid phthalate at $25^{\circ}$. For the former a $P_{\mathrm{H}}$ value of 3.89 and for the latter a value of $3.9 \mathrm{I}$ were obtained, corresponding to hydrogen-ion concentrations of $1.29 \times 10^{-4}$ and $\mathrm{r} .23 \times 10^{-4}$, respectively. These measurements show that a twofold dilution in fairly concentrated solutions of potassium acid phthalate produces but little change in the hydrogen-ion concentration. This would seem to indicate that the salt at this concentration ionizes chiefly into $\mathrm{K}^{+}$ and $\mathrm{HC}_{8} \mathrm{H}_{4} \mathrm{O}_{4}-$.

Potassium Phthalate.-Potassium phthalate is a very hygroscopic sub-

${ }^{1}$ In Col. 4 the molectular conductivity has been reduced by subtracting the specific conductivity of the water, the average of which was $1.4 \times 10^{-8}$ reciprocal ohms, from the specific conductivity as measured. Kendall (ThIs Journal, 39, 7 (19I7)) states that for salts of weak acids we have the rule that the ideal specific conductivity is intermediate between the uncorrected and the water-corrected values. In the absence of any guide as to what correction actually should be applied we have used half the water correction and given the "partly corrected" result in the last column of Table I, merely to show its magnitude. This question of the correction for conductivity of the solvent is still under discussion. Washburn (ThIS JourNaL, 40, IO6 (1918)), indeed, takes issue with Kendall, and maintains that the other impurities besides carbon dioxide affect in an appreciable degree the conductivity of the water used as solvent. Further, practically all discussion of electrolytic conductance extant is confined to binary electrolytes, and as we are dealing with an acid salt and a weak dibasic acid the situation is very complex. 
stance and consequently would be very difficult to recrystallize and weigh out for standard solutions. A standard solution $(0.05 M)$ was prepared by dissolving the equtivalent amount of potassium acid phthalate and adding standard potassium hydroxide solution to neutrality with phenolphthalein. A second solution was prepared by weighing out phthalic

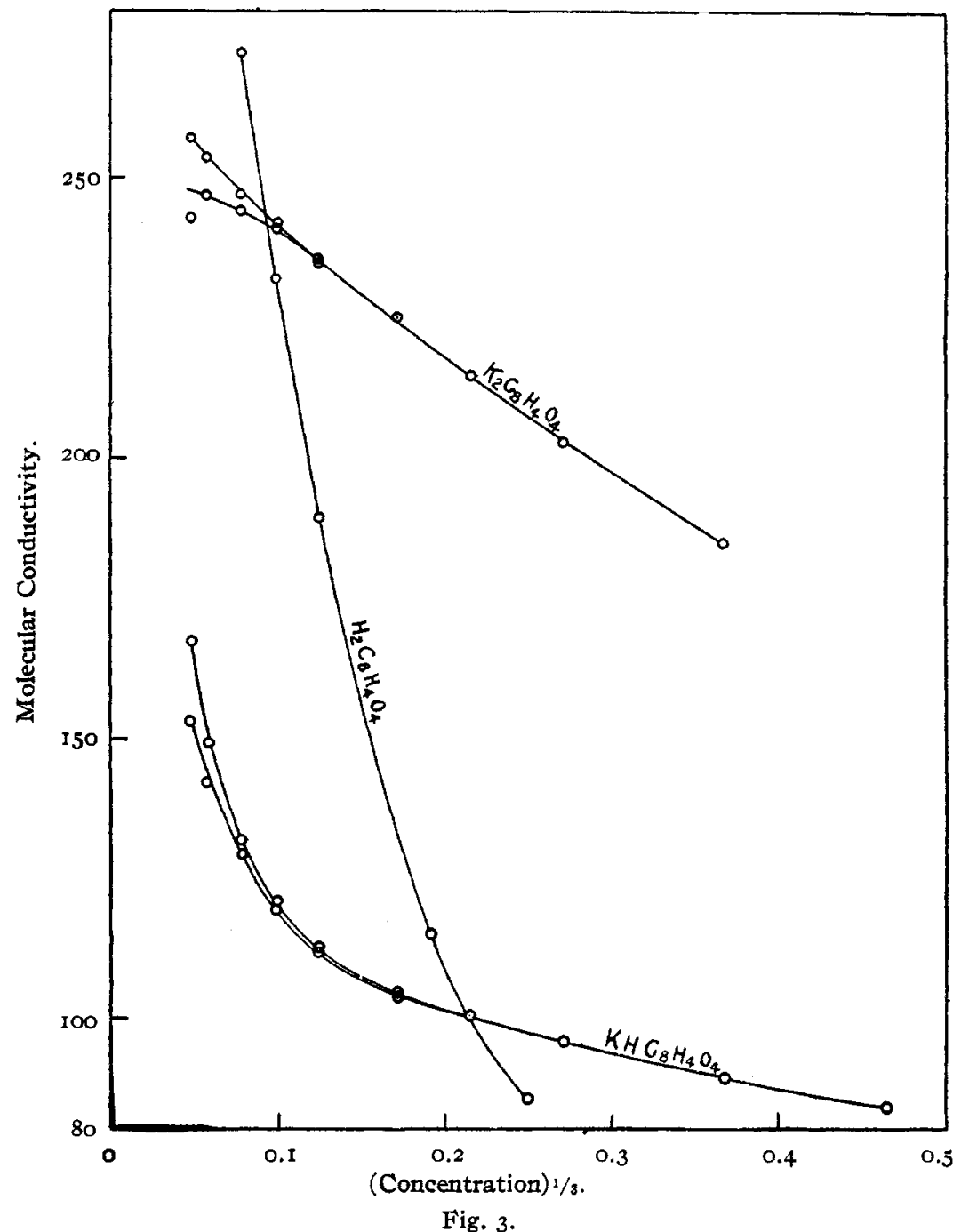

acid anhydride and adding the requisite amount of potassium hydroxide solution. In this way it was found that the alkali solution which had been prepared to be as free from carbonate as possible contained a negligible amount of this impurity. For although twice as much of the alkali 
was used in preparing the solution from the anhydride as from the acid potassium salt there was no appreciable difference in the conductivity of the two solutions. The values obtained are shown in Table II:

table II.-Conductivity of Potassium Phthaiate.

$\begin{array}{rcccc}\text { V. } & \text { Sp. cond. } \times 10^{3} & \begin{array}{c}\text { Mol. cond. } \\ \text { uncorrected. }\end{array} & \begin{array}{c}\text { Mol. cond. } \\ \text { corrected } \\ \text { for cond. H2O. }\end{array} & \begin{array}{c}\text { Mol. cond. } \\ \text { partly } \\ \text { corrected. }\end{array} \\ 20 & 9.240 & 184.8 & 184.8 & 184.8 \\ 50 & 4.058 & 202.9 & 202.8 & 202.9 \\ 100 & 2.148 & 214.8 & 214.7 & 214.7 \\ 200 & 1.125 & 225.0 & 224.7 & 224.9 \\ 500 & 0.471 & 235.5 & 235.0 & 235.0 \\ 1000 & 0.242 & 242.0 & 241.0 & 241.0 \\ 2000 & 0.1235 & 247.0 & 244.0 & 246.0 \\ 5000 & 0.0507 & 253.5 & 247.0 & 250.0 \\ 10000 & 0.0257 & 257.0 & 243.0 & 250.0\end{array}$

The molecular conductivity of normal potassium phthalate is much higher than that of potassium acid phthalate, the value for the former being at each concentration about 100 reciprocal ohms greater than that of the latter. The conductivity of phthalic acid has been determined by White and Jones; ${ }^{2}$ over a part of the range it is intermediate between that of the two salts.

We endeavored to obtain a value of $\lambda_{\circ}$ to use in determining the degree of ionization of the neutral and of the acid potassium phthalate, trying out various formulas which have been suggested in the literature. ${ }^{3}$ These formulas, however, do not give comparable results and accordingly the value of $\lambda_{0}$ is still so uncertain that it is useless to present any values of the degree of ionization of these salts. See Fig. 2.

WAshrngton, D. C.

$1 \mathrm{Cf}$, footnote to Table I.

${ }^{2}$ Am. Chem. J., 44, 187 (1910).

${ }^{3}$ Ostwald and Bredig, Z. physik. Chem., 13, 191 (1894); Kohlrausch, Wiss. Abh. Phys. Tech. Reichanstalt, 3, I55 (I900); Z. Elektrochem., I3, I33 (1907); Noyes and Falk, This Journal, 34, 462 (I9I2); Kraus and Bray, Ibid., 35, 1315-1434 (I9I3); Ostwald, Physiko-Chemische Messungen; Derick, Thrs Joursal, 36, 2268 (1914); White and Jones, Am. Chem. J., 44, I87 (1910); Kendall, J. Chem. Soc., ror, 1275 (1912); Chandler, This Journal, 30, 694 (1908); Szyszkowski, Medd. Nobel Inst., 3, No. 2 (1914); 3, No. II (1916); Lewis, $Z$. physik. Chem., 70, 218 (1909); Walden, $Z$. anorg. Chem., 25, 209 (1900); 29, 37 I (1902); Thrs JournaL, 35, 1649 (r913); Kendall, Ibid., 39, 2323 (1917). 